\title{
A new 500 kb haplotype associated with high CD8+ T-lymphocyte numbers predicts a less severe expression of hereditary hemochromatosis
}

\author{
Eugénia Cruz*1,2, Chris Whittington ${ }^{3}$, Samuel H Krikler ${ }^{4,5}$, \\ Cláudia Mascarenhas ${ }^{2}$, Rosa Lacerda ${ }^{6}$, Jorge Vieira ${ }^{7}$ and Graça Porto ${ }^{1,2,6}$
}

\begin{abstract}
Address: ${ }^{1}$ Clinical Hematology, Santo António Hospital, Porto, Portugal, ${ }^{2}$ Iron Genes and the Immune System (IRIS), IBMC-Instituto de Biologia Molecular e Celular, Universidade do Porto, Portugal, ${ }^{3}$ Department of Family Practice, University of British Columbia, Vancouver, Canada, ${ }^{4}$ Department of Pathology and Laboratory Medicine, University of British Columbia, Vancouver, Canada, ${ }^{5}$ BC Biomedical Laboratories, Surrey, Canada, ${ }^{6}$ Molecular Immunology and Pathology, ICBAS-Instituto de Ciências Biomédicas de Abel Salazar, Universidade do Porto, Portugal and ${ }^{7}$ Molecular Evolution, IBMC-Instituto de Biologia Molecular e Celular, Universidade do Porto, Portugal
\end{abstract}

Email: Eugénia Cruz* - ecruz@ibmc.up.pt; Chris Whittington - cawhittington@shaw.ca; Samuel H Krikler - Sam.Krikler@fraserhealth.ca; Cláudia Mascarenhas - mcmm@ibmc.up.pt; Rosa Lacerda - rclfigueiredo@yahoo.com.br; Jorge Vieira - jbvieira@ibmc.up.pt;

Graça Porto - gporto@ibmc.up.pt

* Corresponding author

Published: 6 November 2008

BMC Medical Genetics 2008, 9:97 doi:10.1 186/1471-2350-9-97
Received: 10 July 2008

Accepted: 6 November 2008

This article is available from: http://www.biomedcentral.com/I47/-2350/9/97

(c) 2008 Cruz et al; licensee BioMed Central Ltd.

This is an Open Access article distributed under the terms of the Creative Commons Attribution License (http://creativecommons.org/licenses/by/2.0), which permits unrestricted use, distribution, and reproduction in any medium, provided the original work is properly cited.

\begin{abstract}
Background: Hereditary Hemochromatosis $(\mathrm{HH})$ is a common genetic disorder of iron overload where the large majority of patients are homozygous for one ancestral mutation in the HFE gene. In spite of this remarkable genetic homogeneity, the condition is clinically heterogeneous, varying from a severe disease to an asymptomatic phenotype with only abnormal biochemical parameters. The recent recognition of the variable penetrance of the $\mathrm{HH}$ mutation in different large population studies demands the need to search for new modifiers of its phenotypic expression. The present study follows previous observations that MHC class-I linked genetic markers, associated with the setting of CD8+ T-lymphocyte numbers, could be clinically relevant modifiers of the phenotypic expression in $\mathrm{HH}$, and aimed to find new markers that could be used as more reliable prognostic variables.
\end{abstract}

Methods: Haplotype analysis, including seven genetic markers within a I Mb region around the microsatellite D6SI05 was performed in a group of 56 previously characterized C282Y homozygous Portuguese patients. Parameters analyzed in this study were total body iron stores, clinical manifestations related with $\mathrm{HH}$ and immunological parameters (total lymphocyte numbers, CD4+ and CD8+ T-lymphocyte numbers). An independent group of 10 C282Y homozygous patients from Vancouver, Canada, were also included in this study and analyzed for the same parameters.

Results: A highly conserved ancestral haplotype defined by the SNP markers PGBDI-A, ZNFI $93-$ A, ZNFI65-T (designated as A-A-T) was found associated with both abnormally low CD8+ Tlymphocyte numbers and the development of a severe clinical expression of $\mathrm{HH}$. In a small proportion of patients, another conserved haplotype defined by the SNP markers PGBDI-G, ZNFI 93-G, ZNFI65-G (designated as G-G-G) was found associated with high CD8+ T-lymphocyte numbers and a milder clinical expression. Remarkably, the two conserved haplotypes defined in 
Portuguese patients were also observed in the geographically different population of Canadian patients, also predicting CD8+ T-lymphocyte numbers and the severity of disease.

Conclusion: These results may have important implications not only for approaching the question of the penetrance of the hemochromatosis gene in different world populations but also to further narrow the region of interest to find a candidate gene involved in the setting of CD8+ Tlymphocyte numbers in humans.

\section{Background}

Hereditary hemochromatosis $(\mathrm{HH})$ is characterized by an inappropriately high iron absorption causing progressive iron loading of parenchymal cells of the liver and other organs with consequent tissue damage and dysfunction, leading to potentially lethal clinical consequences such as diabetes, liver cirrhosis and hepatocarcinoma [1]. The great majority of $\mathrm{HH}$ patients are homozygous for the C282Y mutation in HFE, a non-classical MHC class-I gene involved in the regulation of iron metabolism [2]. In spite of this great genetic homogeneity, the clinical heterogeneity is variable. Some patients exhibit a clinically severe disease while many $\mathrm{C} 282 \mathrm{Y}$ homozygotes are apparently healthy showing only abnormal biochemical parameters and nonspecific symptoms such as fatigue and arthralgia [3-6]. Although gender, age and environmental factors partially explain the variability observed in iron accumulation and associated clinical presentation, these are not sufficient to explain all the phenotypic heterogeneity observed in clinical practice $[7,8]$. Recently, the recognition of variable penetrance of the $\mathrm{C} 282 \mathrm{Y}$ mutation in different large population screening studies [8-14] has strengthened the need to search for new clinically relevant modifiers of phenotypic expression including new genetic modifiers.

We have previously shown that a large proportion of $\mathrm{HH}$ patients have consistently low CD8+ T-lymphocyte numbers correlating with a more severe expression of iron overload [15-18]. Low total lymphocytes counts, reflective of low CD8+ T-cell counts, were also shown in $\mathrm{HH}$ patients from the north of Portugal [19] and from Alabama (United States) [20] and those numbers were inversely associated with the amount of iron removed by phlebotomies $[19,20]$. The CD8+ T-lymphocyte abnormality was shown to be genetically transmitted, associated with the inheritance of particular HLA haplotypes $[21,22]$. More recent evidence was provided that stable numbers of peripheral blood CD8+ T lymphocytes are partially determined by genetic factors located close to the microsatellite marker D6S105 at the MHC-class-I region, close to the HFE gene $[22,23]$. Importantly, this same genetic region had been proposed some years ago as a putative location for modifiers of iron overload in Australian $\mathrm{HH}$ patients [24]. It is therefore highly probable that a major genetic trait contributing to the CD8+ T-lym- phocyte abnormalities in $\mathrm{HH}$ patients is inherited in particular haplotypes, in linkage disequilibrium with the C282Y mutation, and, directly or indirectly, may contribute to the heterogeneity in the clinical expression of $\mathrm{HH}$.

With the objective of identifying a better marker predicting both the inheritance of CD8+ T-cell numbers and the severity of expression in $\mathrm{HH}$, haplotype analysis (including seven genetic markers within a 1 megabase region around the microsatellite D6S105) was performed in a group of 56 previously characterized C282Y homozygous Portuguese patients. Two different conserved haplotypes, with 500 kilobases $(\mathrm{Kb})$ approximately, were identified and correlated with the phenotypic and clinical variables. In order to extend the significance of the results found in the Portuguese patients to a geographically different population, an additional group of 10 patients from Vancouver, Canada, was tested for the same genetic markers.

\section{Methods \\ Study population}

Two different populations were analyzed in the present study. The first group included $56 \mathrm{HH}$ subjects, all homozygous for the C282Y mutation of the HFE gene, identified between 1985 and 2007 and regularly followed up at the Hemochromatosis Outpatient Clinic of Santo António Hospital, Porto and Predictive and Preventive Genetic Centre, Porto. These subjects were all Caucasians from the north of Portugal and included 45 probands detected in the context of suggestive clinical picture of hemochromatosis, generally with related clinical manifestations, or detected accidentally after a routine test and generally asymptomatic. Twenty-seven were males with mean age at diagnosis $46 \pm 12$ years and 18 were females with mean age at diagnosis $47 \pm 10$ years. Eleven patients were family members detected in the context of systematic family screening programs. These were 4 males with mean age at diagnosis $42 \pm 5$ years and 7 females with mean age at diagnosis $43 \pm 15$ years.

With the objective of extending the results obtained in the Portuguese patients to a geographically distinct population, an additional group of $10 \mathrm{HH}$ patients homozygous for the C282Y mutation followed up at Dr Whittington's practice in Abbotsford, near Vancouver, Canada, were included in this study. Two patients (siblings) were from 
Germany, three patients were from the Netherlands, one was of Irish extraction, one was of mixed English and North American Indian extraction, two were Mennonites and another was adopted with unknown heritage. Five were males (median age at diagnosis $48 \pm 7$ years) and 5 were females (median age at diagnosis $61 \pm 16$ years). Three patients were detected in the context of suggestive clinical picture of hemochromatosis and had clinical symptoms, two were detected in the context of nonspecific clinical symptoms such as arthralgia and fatigue, and three were detected in routine tests and had no symptoms. Finally, two patients were family members detected in the context of family screening programs.

The study was approved by the ethical committee of Santo António Hospital including an informed consent obtained from patients according to the Helsinki declaration.

\section{Clinical characterization of subjects}

Clinical data from the patients included in the study were carefully reviewed from their clinical files by one dedicated physician for each group of patients. The clinical parameters used in the analysis included: biochemical parameters of iron metabolism (TfSat and serum ferritin) determined at diagnosis by standard techniques as described [19], total body iron stores (TBIS) determined by quantitative phlebotomies [25] and the presence of clinical manifestations related to $\mathrm{HH}$.

Clinical evaluation of the group of C282Y homozygous Portuguese patients was previously described in detail elsewhere $[19,26]$. Twenty-five were symptomatic patients presenting with one or more of the following manifestations: liver cirrhosis/fibrosis, diabetes, arthropathy, hypopituitarism, skin pigmentation or cardiac abnormalities, and removed an average of $9.3 \pm 4.7 \mathrm{~g}$ of iron (between 2.5 and $17.6 \mathrm{~g}$ ) by intensive phlebotomies. Twenty-eight were asymptomatic patients presenting with only biochemical evidence of iron overload and removed an average of $4.8 \pm 2.8 \mathrm{~g}$ of iron (between 1.1 and $10.8 \mathrm{~g}$ ) by intensive phlebotomies. Three patients had associated immunological conditions (two were hepatitis B virus carriers and one had a chronic monoclonal expansion of CD8+ T cells) and were a posteriori excluded from clinical analysis.

The group of Canadian patients had a greater heterogeneity in terms of clinical presentation than the Portuguese patients. Three had associated immunological diseases (small cell B lymphoma, celiac disease and Hashimoto's thyroiditis) and one had a viral infectious disease (hepatitis $\mathrm{C}$ infection). In terms of clinical manifestations 5 were symptomatic patients that removed an average of $15.0 \pm$ $11.4 \mathrm{~g}$ of iron (between 2.0 and $28.5 \mathrm{~g}$ ) by phlebotomies and 5 were asymptomatic patients that removed an average of $2.38 \pm 1.7 \mathrm{~g}$ of iron (between 0.5 and $5.0 \mathrm{~g}$ ) by intensive treatment.

\section{Immunological characterization of subjects}

The immunological characterization of patients included the number of peripheral blood total lymphocytes and their sub-populations T-CD8+ and T-CD4+. The T-lymphocyte subpopulations were determined by FACS analysis using anti-CD3, anti-CD4 and anti-CD8 monoclonal antibodies as previously described in detail [21]. For the purpose of phenotypic characterization of patients, total lymphocyte numbers, CD4+ T-lymphocyte numbers and CD8+ T-lymphocyte numbers were considered "low" when they were $\leq 2.12, \leq 0.90$ and $\leq 0.41 \times 10^{6} / \mathrm{ml}$, respectively, and were considered "high" when $>2.12$, > 0.90 and $>0.41 \times 10^{6} / \mathrm{ml}$, respectively, as defined in previous studies of lymphocyte populations in hemochromatosis $[21,22,26]$. These cut-off values were based on the median values of the parameters previously established on a control population from the north of Portugal [21].

\section{Genetic characterization of $\mathrm{HH}$ subjects}

All subjects (56 Portuguese and 10 Canadian) had been previously genotyped for HFE mutations (H63D and $\mathrm{C} 282 \mathrm{Y}$ ) and they are all homozygous for the C282Y mutation. Forty-seven Portuguese HH patients were previously genotyped for microsatellites D6S2222 and D6S105 [22] and this information was included in this study. Genetic data from the Portuguese patients have been partially published [22].

For the purpose of this study, 5 single nucleotide polymorphisms (SNPs) localized in the region around the microsatellite D6S105 in the 6p21.3 region were genotyped in all patients. These SNPs are localized in the following genes: zinc finger and SCAN domain containing 12 (ZSCAN12), piggyBac transposable element derived 1 (PGBD1), zinc finger protein (ZNF) 193, ZNF165 and ZNF184. Selection of SNPs was based on the location in the region and the frequency of alleles. These markers define a region of 1 megabase $(\mathrm{Mb})$ (Figure 1 ) centromeric to $H F E$ approximately $1.4 \mathrm{Mb}$ and telomeric to HLA-A approximately $1.5 \mathrm{Mb}$.

SNP genotyping was performed by gene sequencing. Briefly, genomic DNA (gDNA) was extracted from peripheral blood or stored. gDNA and amplicons containing the selected loci were PCR-amplified using specific primers. Amplicons were then electrophoresed and extracted from the gel with the QIAquick Gel Extraction Kit (Quiagen). Sequencing reactions were prepared with the Big Dye Terminator v1.1 Cycle Sequencing kit (Applied Biosystems) and loaded in an ABI prism 310 Genetic Analyzer Sequencer (Applied Biosystems). 


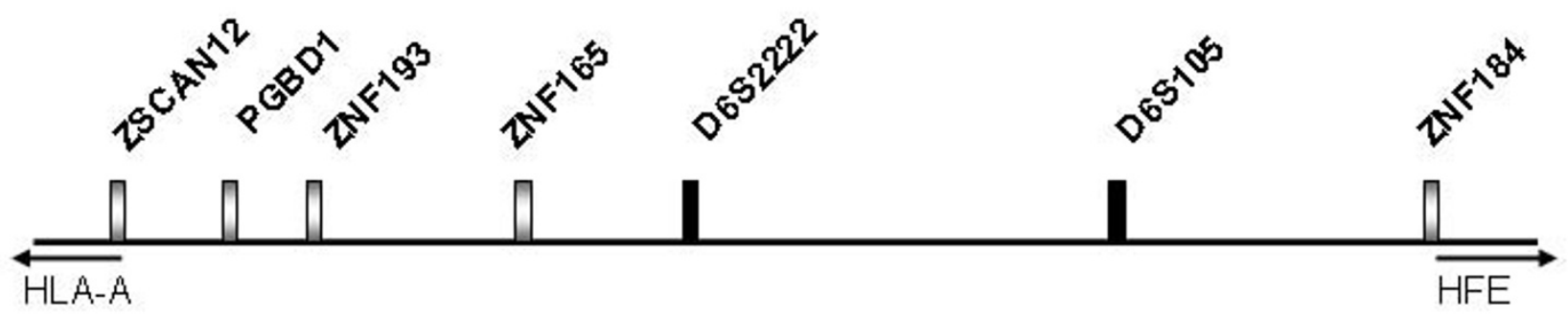

$\overline{100 \text { kbases }}$

Figure I

Physical map of the genetic markers used in the present study and their relative location at scale.

\section{Haplotype definition}

For the purpose of this study, extended haplotypes were inferred using the program PHASE http://www.stat.wash ington.edu/stephens/software.html, as described previously in Vieira et al. 2007 [23]. Extended haplotypes were defined with the information on the genotype of 7 markers: ZSCAN12, PGBD1, ZNF193, ZNF165, D6S2222, D6S105 and ZNF184 (Figure 1). The phase of length polymorphisms at microsatellite markers D6S105 and D6S2222 was known from family studies (data not shown), and this information was used when running PHASE. In few cases $(\mathrm{n}=9)$, information was missing for some individuals at some of the markers scored. In those cases, missing alleles were inferred using PHASE. A total of 14 different extended haplotypes $(1 \mathrm{Mb})$ were defined in the group of 56 Portuguese $\mathrm{HH}$ subjects and their fre- quencies estimated in the population (Table 1). More restricted haplotypes $(500 \mathrm{~Kb})$ were further defined according to the pattern of allele conservation (conserved haplotypes).

For the purpose of defining the haplotypes in the 10 Canadian HH patients the PHASE program was run with the information on the genotype of 5 SNP markers (ZSCAN12, PGBD1, ZNF193, ZNF165 and ZNF184) determined in this population. The haplotypes found were the same as described in the Portuguese HH patients.

\section{Statistical analysis}

Association studies between T-lymphocyte subpopulations and the genetic markers were performed in the Portuguese $\mathrm{HH}$ patients. Association studies were first performed on a

Table I: Inferred haplotypes present in a sample of 56 Portuguese $\mathrm{HH}$ patients

\begin{tabular}{|c|c|c|c|c|c|c|c|c|c|}
\hline \# & ZSCANI 2 & PGBD I & ZNFI93 & ZNF 165 & D6S2222 & D6SI05 & ZNF I 84 & $\mathbf{N}$ & Frequency \\
\hline I & A & $\mathbf{A}$ & A & $\mathbf{T}$ & 247 & 150 & G & 82 & $73.2 \%$ \\
\hline 2 & G & $\mathbf{A}$ & A & $\mathbf{T}$ & 247 & 150 & G & 8 & $7.1 \%$ \\
\hline 3 & A & $\mathbf{A}$ & $\mathbf{A}$ & $\mathbf{T}$ & 249 & 150 & G & 5 & $4.5 \%$ \\
\hline 4 & A & A & $\mathbf{A}$ & $\mathbf{T}$ & 247 & 160 & $\mathrm{G}$ & 1 & $0.9 \%$ \\
\hline 5 & A & $\mathbf{A}$ & A & $\mathbf{T}$ & 247 & 148 & G & 1 & $0.9 \%$ \\
\hline 6 & $\mathbf{A}$ & $\mathbf{A}$ & $\mathbf{A}$ & $\mathbf{T}$ & 249 & 158 & G & 1 & $0.9 \%$ \\
\hline 7 & $\mathbf{A}$ & $\mathbf{A}$ & A & $\mathbf{T}$ & n.a. & 170 & G & 1 & $0.9 \%$ \\
\hline 8 & G & A & A & $\mathbf{T}$ & 247 & 148 & G & 1 & $0.9 \%$ \\
\hline 9 & $\mathbf{A}$ & $\mathbf{A}$ & A & $\mathbf{T}$ & 247 & 150 & $\mathrm{~T}$ & 1 & $0.9 \%$ \\
\hline 10 & A & A & A & $\mathbf{T}$ & 245 & 150 & $\mathrm{~T}$ & 2 & $1.8 \%$ \\
\hline II & G & $\mathbf{A}$ & $\mathbf{A}$ & $\mathbf{T}$ & 247 & 150 & $\mathrm{~T}$ & 2 & $1.8 \%$ \\
\hline 12 & G & G & G & G & 249 & 150 & G & 4 & $3.6 \%$ \\
\hline 13 & G & G & G & G & 249 & 160 & G & 2 & $1.8 \%$ \\
\hline 14 & G & $A$ & G & G & 249 & 150 & $\mathrm{~T}$ & 1 & $0.9 \%$ \\
\hline
\end{tabular}

Alleles in bold represent conserved haplotype regions.

A: adenine; G: guanine; T: thymine. For microsatellite markers the size of the amplified PCR product is given (in base pairs). n.a.: not available 
single locus basis (for the seven markers included in the extended haplotypes) followed by analysis of the more restricted conserved haplotypes (see above). Moreover, since each subject carries two haplotypes, a third set of analyses was performed considering the combination of the two inherited conserved haplotypes. Finally, the combination of conserved haplotypes was used to analyze its impact on the clinical expression of the disease, both in terms of the amount of iron mobilized by phlebotomies (TBIS) and the clinical manifestations. In order to validate the results obtained with the analysis of the Portuguese $\mathrm{HH}$ patients, the impact of the combined haplotypes on both the number of CD8+ T cells and the phenotypic expression of $\mathrm{HH}$ was further analyzed including the whole group of patients (Portuguese and Canadian).

For the statistical analyses that include CD8+ T lymphocytes, patients with clinical conditions known to influence those numbers (such as autoimmune or viral diseases) were excluded (three Portuguese patients, two carriers of hepatitis B virus and one with chronic monoclonal expansion of CD8+ $\mathrm{T}$ cells, and 4 Canadian patients with: hepatitis C infection, small cell B lymphoma, celiac disease and Hashimoto's thyroiditis).

Group means were compared by the Student T-test when two groups were analyzed or by one-way analysis of variance (ANOVA) when more than two groups were analyzed. The Chi-square test was used to test the fitness of data to the normal distribution. Independence between categorical data was tested using the Chi-Square test. The Yates correction was used when small samples $(<5)$ were tested. All statistical tests were performed at 0.05 level of significance and all $p$ values are two-sided. Data were analyzed by Statgraphics software (Statgraphics Graphics System, version 7.0).

\section{Results}

\section{Definition of haplotypes in a I $\mathrm{Mb}$ region around the microsatellite D6SI 05 in Portuguese $\mathbf{H H}$ subjects}

For the characterization of a $1 \mathrm{Mb}$ region in haplotypes carrying the $\mathrm{C} 282 \mathrm{Y}$ mutation, information on the genotype of 7 genetic markers, ZSCAN12, PGBD1, ZNF193, ZNF165, D6S2222, D6S105 and ZNF184, was used (Figure 1). A total of 112 extended haplotypes were defined in 56 Portuguese HH subjects (see Material and Methods). Haplotypes were aligned according to the similarity to the most common haplotype. Results are shown in Table 1. The predominant extended haplotype was found in $73 \%$ (82/112) of chromosomes and is defined by: ZSCAN12A, PGBD1-A, ZNF193-A, ZNF165-T, D6S2222-247, D6S105-150, ZNF184-G (haplotype \#1, Table 1). The high frequency of this haplotype suggests that it is the ancestral haplotype in the evolutionary history of the
C282Y mutation in this population. Several extended haplotypes differing from the ancestral in only 1 or 2 markers are found with frequencies of 0.9 to $7.1 \%$ (haplotypes \#2 to \#11, Table 1). All these extended haplotypes maintain a highly conserved region of approximately 500 Kb defined by PGBD1-A; ZNF193-A; ZNF165-T (see Table 1).

Only 3 extended haplotypes differing from the ancestral in more than 5 markers were found in this population of patients. Two of them (haplotypes \#12 and \#13) have a new conserved region defined by: ZSCAN12-G, PGBD1G, ZNF193-G, ZNF165-G, D6S2222-249 and were found with a global frequency of 5.4\% (6/112).

\section{Association of CD8+ T-lymphocyte numbers with genetic markers in the region around the microsatellite D6SI 05 in Portuguese $\mathrm{HH}$ subjects}

\section{I. Single locus analysis}

For the purpose of investigating the influence of the region under study on CD8+ T-lymphocyte numbers, association studies were first performed between CD8+ Tlymphocyte numbers and the alleles of each genetic marker by one-way ANOVA. Allele diversity in this group of $\mathrm{HH}$ patients is evident for the markers ZSCAN12, D6S2222, D6S105 and ZNF184 (see Table 1). No association was found between any of these individual markers and the number of CD8+ $\mathrm{T}$ lymphocytes (data not shown). In contrast, a statistically significant association was found between CD8+ T-lymphocyte numbers and each of the SNP markers PGBD1 ( $\mathrm{p}=0.0109)$, ZNF193 ( $\mathrm{p}$ $=0.027)$ and ZNF165 ( $\mathrm{p}=0.027)$. The alleles PGBD1-A, ZNF193-A and ZNF165-T were associated with "low" CD8+ T-cell counts $(0.37 \pm 0.17,0.37 \pm 0.17$ and $0.37 \pm$ $0.17 \times 10^{6} / \mathrm{ml}$, respectively) while the alleles PGBD1-G, ZNF193-G and ZNF165-G were associated with "high" CD8+ T-cell counts $(0.55 \pm 0.14,0.51 \pm 0.15$ and $0.51 \pm$ $0.15 \times 10^{6} / \mathrm{ml}$, respectively) .

A statistically significant result was observed when associations of total lymphocyte counts and each of the SNP markers PGBD1 ( $\mathrm{p}=0.008)$, ZNF193 ( $\mathrm{p}=0.038)$ and ZNF165 ( $p=0.038$ ) were tested. The alleles PGBD1-A, ZNF193-A and ZNF165-T were associated with "low" total lymphocyte counts $(2.00 \pm 0.58,2.01 \pm 0.58$ and $2.01 \pm$ $0.58 \times 10^{6} / \mathrm{ml}$, respectively) while the alleles PGBD1-G, ZNF193-G and ZNF165-G were associated with "high" total lymphocyte counts $(2.65 \pm 0.42,2.48 \pm 0.58$ and $2.48 \pm 0.58 \times 10^{6} / \mathrm{ml}$, respectively). No statistically significant associations were found for total lymphocyte counts and any of the other markers used (data not shown). No statistically significant effect was found on the numbers of CD $4+\mathrm{T}$ cells with any of the genetic markers tested (data not shown). 


\subsection{Analyses of conserved haplotypes}

It is relevant to note that the 3 alleles associated with "low" CD8+ T-cell numbers are found in linkage disequilibrium in the ancestral haplotype (PGBD1-A, ZNF193-A, ZNF165-T). These define a restricted haplotype of approximately $500 \mathrm{~Kb}$ from now on designated as A-A-T haplotype. In contrast, the alleles associated with "high" CD8+ T-cell numbers are found in linkage disequilibrium in the new conserved haplotype defined by PGBD1-G, ZNF193G, ZNF165-G. This restricted haplotype of approximately $500 \mathrm{~Kb}$ is from now on designated as G-G-G haplotype. The association of CD8+ T-lymphocyte numbers with the A-A-T haplotype (average CD8+T cells $=0.37 \pm 0.17 \times 10^{6} /$ $\mathrm{ml}$ ) and with the G-G-G haplotype (average CD8+ T cells $\left.=0.55 \pm 0.14 \times 10^{6} / \mathrm{ml}\right)$ is more significant $(\mathrm{p}=0.0108$, one-way-ANOVA) than the association of CD8+ T cells with any of the markers alone.

\subsection{Analyses of combined conserved haplotypes}

To further investigate the association found between the conserved haplotypes and CD8+ T-cell numbers, subjects were divided according to the combination of their two haplotypes. The conserved haplotype A-A-T was found in homozygosity in 50 subjects (89\%) and the new conserved haplotype G-G-G was found always in heterozygosity with the ancestral in 6 subjects (11\%).

A statistically significant result $(\mathrm{p}=0.0092)$ was observed when association studies were performed between CD8+ T-lymphocyte numbers and subjects divided according to the combination of inherited haplotypes. Subjects carrying the two ancestral haplotypes (A-A-T $\times$ A-A-T) had significantly lower CD8+ T-cell counts $\left(0.35 \pm 0.17 \times 10^{6} /\right.$ $\mathrm{ml}$ ) and subjects carrying the combination of the new conserved haplotype with the ancestral haplotype (G-G-G $\times$ A-A-T) had significantly higher CD8+ T-cell counts $(0.55$ $\pm 0.14 \times 10^{6} / \mathrm{ml}$ ) (Table 2).

A statistically significant result $(\mathrm{p}=0.0081)$ was also observed when association studies were performed between total lymphocyte numbers in subjects with two A-A-T haplotypes $\left(1.98 \pm 0.57 \times 10^{6} / \mathrm{ml}\right)$ and subjects that carry the G-G-G haplotype $\left(2.65 \pm 0.42 \times 10^{6} / \mathrm{ml}\right)$ (Table 2 ). No statistically significant differences were found in CD4+ T-lymphocyte numbers in subjects carrying or not the G-G-G haplotype (Table 2).

\section{Implication of the conserved region defined by PGBDI- ZNFI93-ZNFI65 on the clinical expression of $\mathrm{HH}$ on Portuguese patients}

The conserved region defined by the markers PGBD1ZNF193-ZNF165 is part of the MHC class-I region previously shown to be associated with setting the level of CD8+ T-cell numbers [22]. This MHC class-I region was also shown to have an impact on the clinical expression of $\mathrm{HH}[22]$, therefore we tested the hypothesis that the conserved haplotypes described here (PGBD1-ZNF193ZNF165) could also be associated with the phenotypic expression of HH. To investigate this hypothesis we analyzed the levels of TBIS and the presence of clinical manifestations of the disease in subjects divided according to the presence of the haplotypes A-A-T and G-G-G.

As shown in Table 2 the subjects heterozygous for the GG-G haplotype $(n=6)$ have a much less severe expression of the disease than subjects homozygous for the A-A-T haplotype, as shown by the statistically significant lower levels of TBIS and the absence of clinical manifestations of the disease of the former. These differences were not

Table 2: Clinical, biochemical and immunological characterization of Portuguese HH patients, according to the combination of the two inherited conserved haplotypes*

\begin{tabular}{|c|c|c|c|}
\hline & $\begin{array}{l}\text { A-A-T } \times \text { A-A-T } \\
(n=46)\end{array}$ & $\begin{array}{l}\text { G-G-G } \times \text { A-A-T } \\
(n=6)\end{array}$ & $\mathbf{P} * *$ \\
\hline Age (years) & $46 \pm 12$ & $37 \pm 8$ & n.s. \\
\hline Male/Female & $25 / 21$ & $3 / 3$ & \\
\hline Transferrin saturation (\%) & $87 \pm 17$ & $83 \pm 13$ & n.s. \\
\hline Serum ferritin $(\mathrm{ng} / \mathrm{ml})$ & $1774 \pm 1848$ & $701 \pm 1124$ & n.s. \\
\hline TBIS (g) & $7.58 \pm 4.58$ & $3.04 \pm 1.52$ & 0.035 \\
\hline Symptomatic patients & $54 \%(25 / 46)$ & $0 \%(0 / 6)$ & 0.04 \\
\hline Total CD8+ cells $\left(\times 10^{6} / \mathrm{ml}\right)$ & $0.35 \pm 0.17$ & $0.55 \pm 0.14$ & 0.0092 \\
\hline Total CD4+ cells (× 106/ml) & $0.96 \pm 0.37$ & $1.24 \pm 0.40$ & n.s. \\
\hline Total lymphocytes $\left(\times 10^{6} / \mathrm{ml}\right)$ & $1.98 \pm 0.57$ & $2.65 \pm 0.42$ & $0.008 I$ \\
\hline
\end{tabular}

\footnotetext{
* Conserved haplotypes are defined by SNP markers PGBDI-ZNFI93-ZNFI65 (see Haplotype definition in Material and Methods). Only one patient did not have any of these two conserved haplotypes and was not included in this analysis.

** Statistically significant differences between groups $(P)$ were tested using Student's T-test (for mean values) or the Chi-square test with Yates correction (for categorical data). Parameters are expressed as mean \pm standard deviation, except percentage of symptomatic patients. Estimation of total body iron stores (TBIS) was obtained in 37 patients with the haplotypes A-A-T $\times$ A-A-T and in 5 patients with the haplotypes G-G-G $\times$ A-A-T.
} 
Table 3: Clinical and immunological characterization and inferred haplotypes present in a sample of 10 Canadian HH patients

\begin{tabular}{|c|c|c|c|c|c|c|c|c|c|c|c|c|c|c|c|c|c|c|}
\hline \multirow[b]{2}{*}{ ID } & \multirow[b]{2}{*}{ Gender } & \multirow{2}{*}{$\begin{array}{l}\text { Age } \\
\text { (years) }\end{array}$} & \multirow{2}{*}{$\begin{array}{r}\text { TfSat } \\
\text { (\%) }\end{array}$} & \multirow{2}{*}{$\begin{array}{l}\text { Ferritin } \\
(\mathrm{ng} / \mathrm{ml})\end{array}$} & \multirow{2}{*}{$\begin{array}{r}\text { TBIS } \\
\text { (g) }\end{array}$} & \multirow{2}{*}{$\begin{array}{l}\text { Associated } \\
\text { diseases }\end{array}$} & \multirow{2}{*}{\multicolumn{2}{|c|}{$\begin{array}{c}\text { CD4+ CD8+ } \\
(\times 106 / \mathrm{ml})\end{array}$}} & \multicolumn{5}{|c|}{ Haplotype I } & \multicolumn{5}{|c|}{ Haplotype 2} \\
\hline & & & & & & & & & ZSCANI 2 & PGBDI & ZNFI93 & ZNFI65 & ZNFI84 & ZSCANI 2 & PGBDI & ZNFI93 & ZNFI65 & ZNFI84 \\
\hline 1 & M & 52 & 96 & 2210 & 5.0 & & 0.95 & 0.26 & A & A & A & $\mathbf{T}$ & G & A & A & A & $\mathbf{T}$ & G \\
\hline 2 & M & 54 & 97 & 1618 & 12.0 & & 0.97 & 0.17 & A & A & A & $\mathbf{T}$ & G & A & A & A & $\mathbf{T}$ & G \\
\hline 3 & $\mathrm{~F}$ & 65 & 95 & 1002 & 7.5 & & 0.30 & 0.14 & A & A & A & $\mathbf{T}$ & G & A & A & A & $\mathbf{T}$ & G \\
\hline 4 & $\mathrm{~F}$ & 63 & n.a. & 2550 & 28.5 & & 0.66 & 0.21 & A & A & A & $\begin{array}{lll}\mathbf{T} & \\
\end{array}$ & G & G & A & A & $\mathbf{T}$ & $T$ \\
\hline 5 & M & 43 & n.a. & n.a. & 25.0 & $\begin{array}{c}\text { Hepatitis C } \\
\text { infection }\end{array}$ & 0.80 & 0.43 & A & A & A & $\mathbf{T}$ & G & A & A & A & $\mathbf{T}$ & G \\
\hline 6 & $\mathrm{~F}$ & 61 & 60 & 500 & 2.0 & Celiac disease & 0.93 & 0.53 & A & A & A & $\mathbf{T}$ & G & G & A & A & $\mathbf{T}$ & $T$ \\
\hline 7 & $\mathrm{~F}$ & 35 & 95 & 82 & 0.5 & $\begin{array}{c}\text { Hashimoto's } \\
\text { thyroiditis }\end{array}$ & 0.79 & 0.50 & A & $\mathbf{A}$ & $\mathbf{A}$ & $\mathbf{T}$ & G & A & A & A & $\mathbf{T}$ & G \\
\hline 8 & $M$ & 51 & 83 & 646 & 2.6 & & 0.55 & 0.43 & A & A & A & G & $\mathrm{T}$ & A & A & A & $\mathbf{T}$ & $\mathrm{T}$ \\
\hline 9 & $\mathrm{~F}$ & 80 & 79 & 463 & 1.7 & $\begin{array}{l}\text { Small cell B } \\
\text { lymphoma }\end{array}$ & 0.64 & 0.40 & G & G & G & G & G & G & A & A & $\mathbf{T}$ & $T$ \\
\hline 10 & M & 39 & 45 & 695 & 2.1 & & 1.01 & 0.58 & G & G & G & G & G & G & G & G & G & $\mathrm{T}$ \\
\hline
\end{tabular}

M: male; F: female. Tfsat: transferrin saturation. n.a.: not available.

Alleles in bold represent conserved haplotype regions. Text in grey highlight subjects with associated diseases. 
reflected in the levels of TfSat and serum ferritin at diagnosis (Table 2).

\section{Extension of the study done in Portuguese patients to a geographically different population of patients}

Results described in this work showed that a conserved region around the microsatellite D6S105, defined by the markers PGBD1-ZNF193-ZNF165, is associated with CD8+ T-lymphocyte numbers and with the severity of the clinical expression in Portuguese HH patients. To extend this study to a different population of patients we studied a group of Canadian HH patients $(\mathrm{n}=10)$. These patients were genotyped for the 5 SNP markers and total lymphocyte counts, and $\mathrm{CD} 4+$ and $\mathrm{CD} 8+$ subpopulations were also determined (see Material and Methods). A summary of data from these patients is shown in Table 3.

The majority of these patients $(5 / 10)$ were homozygous for the extended haplotype defined by ZSCAN12-A, PGBD1-A, ZNF193-A, ZNF165-T, ZNF184-G, as found in

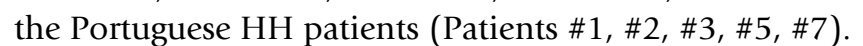
Moreover, some diversity was found in the markers ZSCAN12 and ZNF184 (patient \#4, \#6) but these patients were homozygous for the same highly conserved haplotype PGBD1-A, ZNF193-A, ZNF165-T (A-A-T haplotype) as found in the Portuguese $\mathrm{HH}$ patients. Interestingly, patients with the haplotype A-A-T (patients \#1, \#2, \#3, \#4, after exclusion of patients \#5, \#6 and \#7 because of the associated diseases) were the ones with the lowest levels of CD8+ T lymphocytes and with the more severe forms of iron overload (Table 3 ).

In this group of patients it was identified for the first time one patient homozygous for the new conserved haplotype G-G-G (patient \#10). This patient had the highest number of CD8+ T cells $\left(0.58 \times 10^{6} / \mathrm{ml}\right)$ and had a mild form of iron overload (TBIS $=2.1 \mathrm{~g}$, Table 3 ).

One patient was found to be heterozygous for the new conserved haplotype G-G-G (patients \#9). In this patient the number of CD8+ T cells and the clinical expression of $\mathrm{HH}$ could be confounded by the presence of a small cell B lymphoma.

\section{Global analysis of the conserved haplotypes on CD8+ T- lymphocyte numbers and the clinical expression of $\mathrm{HH}$}

When results from both populations were pooled, similar results were obtained. For the pooled analysis, patients were divided according to the combination of the inherited conserved haplotypes in three groups: patients homozygous for the ancestral A-A-T haplotype $(\mathrm{n}=50)$, patients heterozygous for the G-G-G haplotype $(n=6)$ and homozygous for the G-G-G haplotype $(n=1)$. The results illustrated in Figure 2 clearly show that all patients carrying the new conserved haplotype G-G-G, either in heterozygosity or in homozygosity, have "high" CD8+ Tlymphocyte numbers and a mild expression of iron overload. All patients with severe iron overload ( $>5 \mathrm{~g}$ ) or with "low" CD8+ T-cell counts are homozygous for the haplotype A-A-T. Globally, the combination of the conserved haplotypes was significantly associated with both CD8+ T-lymphocyte numbers and the amount of iron overload measured by TBIS. Subjects homozygous for the A-A-T haplotype had statistically significant lower average values of CD 8+ T-lymphocyte numbers $\left(0.34 \pm 0.17 \times 10^{6} / \mathrm{ml}\right)$ in comparison to carriers (heterozygous or homozygous) for the G-G-G haplotype $\left(0.55 \pm 0.12 \times 10^{6} / \mathrm{ml}\right)(\mathrm{p}=0.0022$, Student T-test). Accordingly, statistically significant higher values of TBIS were found in A-A-T homozygous subjects $(8.33 \pm 5.64 \mathrm{~g})$ in comparison with G-G-G carriers $(2.88 \pm$ $1.41 \mathrm{~g})(\mathrm{p}=0.024$, Student T-test).

\section{Discussion}

This study followed previous observations that MHC class-I linked genetic markers associated with the setting of CD8+ T-cell numbers could be relevant modifiers of the clinical expression in $\mathrm{HH}$. The study aimed to find new genetic markers that could be used as more reliable prognostic variables in the clinical management of $\mathrm{HH}$ patients and also to further narrow the region of interest to find a candidate gene involved in the setting of CD8+ T-lymphocyte numbers in humans.

The results confirmed that a highly conserved $500 \mathrm{~Kb}$ ancestral haplotype defined by the SNP markers PGBD1A, ZNF193-A, ZNF165-T (A-A-T haplotype) marks the inheritance of "low" CD8+ T-lymphocyte numbers and predicts the development of a severe clinical expression of $\mathrm{HH}$ (in terms of iron overload and clinical manifestations). In a small proportion of patients, a new conserved haplotype defined by the SNP markers PGBD1-G, ZNF193-G, ZNF165-G (G-G-G haplotype) was found associated with both the inheritance of "high" CD8+ Tlymphocyte numbers and a milder clinical expression of HH. Very interestingly, the two conserved haplotypes defined in Portuguese patients, were also observed in another geographically different population of Canadian patients, also predicting CD8+ T-lymphocyte numbers and the severity of disease, supporting the view that they most probably are descendents of the same common north European ancestor as the Portuguese patients and therefore may carry the same genetic modifiers. When results of both populations were analyzed together (Figure 2) it was evident that the subjects homozygous for the A-A-T haplotype $(n=50)$ had the lowest average values of CD8+ T cells and highest average levels of TBIS. However there is still some heterogeneity in this group of patients, $28 \%(14 / 50)$ of them presenting with "high" CD8 + T cells and $29 \%(12 / 41)$ presenting a moderate or mild iron overload (TBIS $<5 \mathrm{~g}$ ). In contrast, all subjects hetero- 

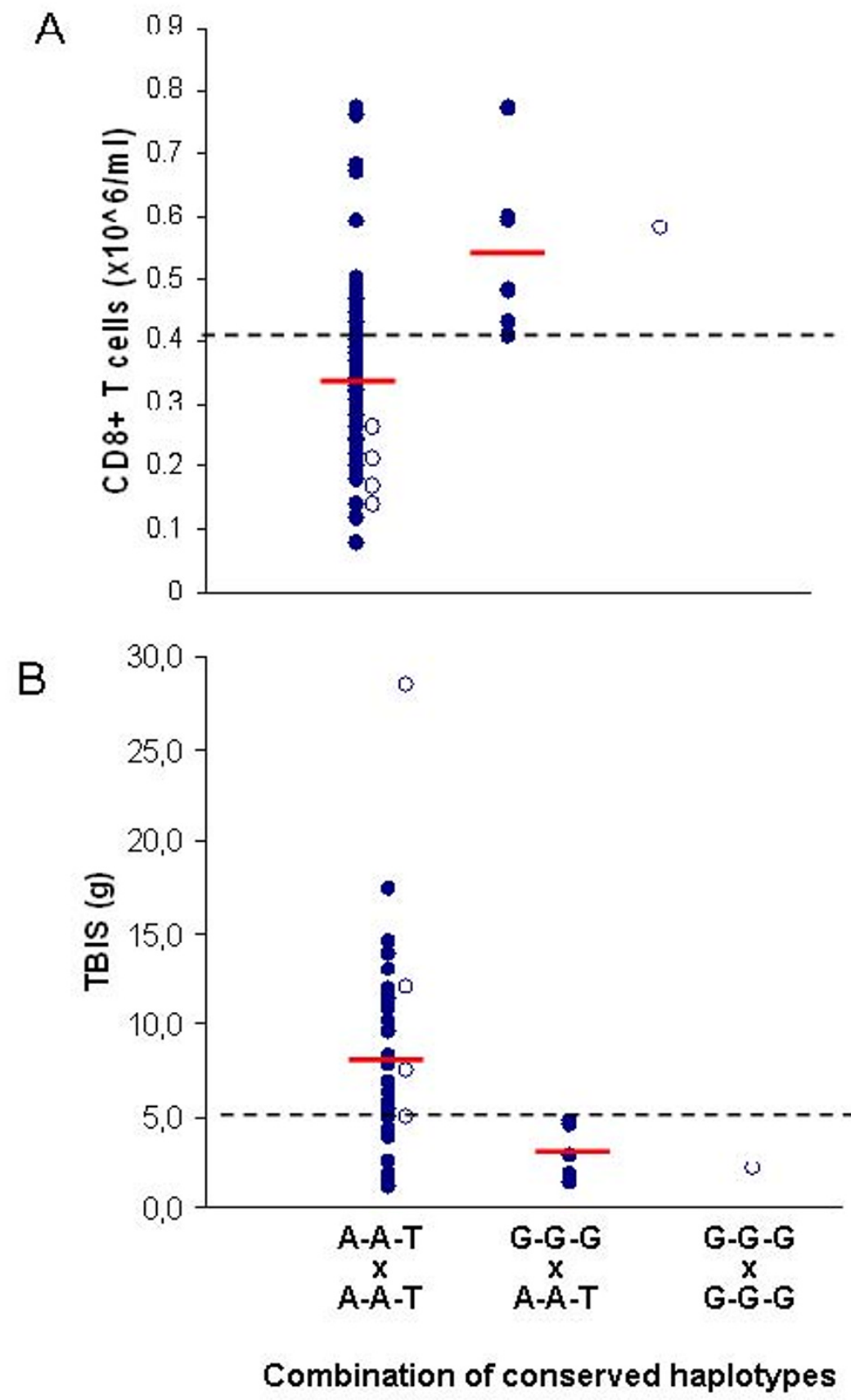

\section{Figure 2}

Distribution of CD8+ T-lymphocyte numbers (A) and of total body iron stores (B) in HH patients. Distribution of CD8+ T-lymphocyte numbers (A) and of total body iron stores (TBIS) (B) in all HH patients (Portuguese and Canadian), according to the combination of the conserved haplotypes (defined by SNP markers PGBDI-ZNFI93-ZNFI65), which divide subjects in three groups: patients homozygous for the ancestral A-A-T haplotype $(n=50)$, patients heterozygous for the $G-G-G$ haplotype $(n=6)$ and homozygous for the $G-G-G$ haplotype $(n=I)$. Dashed lines represent: $(A)$-the median value of $C D 8+T-$ cells (see Material and Methods); (B)-level of TBIS above which iron stores is considered severe. Average values are shown in red lines. Open circles represent Canadian patients. 
zygous for the new conserved haplotypes G-G-G $(n=6)$ and the only subject homozygous for the G-G-G haplotypes had CD8+ T-cell numbers $>0.41 \times 10^{6} / \mathrm{ml}$ and levels of TBIS $<5 \mathrm{~g}$. These results might be explained by the existence in this region of a genetic trait associated with CD8+ T-lymphocyte numbers modifying the phenotype of iron overload in $\mathrm{HH}$. The fact that there is a high heterogeneity in CD8+ T-cell numbers and, consequently in TBIS, in the group of subjects carrying two copies of the A-A-T haplotype is not surprising. Vieira and co-workers [23] stated that individuals with genetically determined "low" CD8+ T cells may under some circumstances have "high" CD8+ T lymphocytes but the opposite is unexpected [23]. Subjects carrying the new conserved G-G-G haplotype were found in the present study only in a small proportion of cases. One may speculate, however, that they may eventually represent the tip of an iceberg where this haplotype could be common in the population of asymptomatic C282Y homozygous subjects. One limitation of this study is the fact that large numbers of asymptomatic or mildly affected hemochromatosis subjects were not available, as expected by the fact that they do not search for medical care. This study should be extended to test, in larger worldwide spread populations, if the G-G-G haplotype is also a marker of clinical expression of $\mathrm{HH}$ subjects detected in large population screening studies where a high proportion of subjects do not seem to express the disease [9-11].

Finally, the present results may have important implications in future strategies to narrow the region of interest to find a candidate gene involved in the settings of CD8+ Tlymphocyte numbers. Previous work from our group in C282Y homozygous patients [22] and in control subjects [23] had shown results suggesting that the gene(s) regulating CD8+ T lymphocytes is localized in the vicinity of the microsatellite D6S105. This was in accordance with previous work by Pratiwi et al. [24] that showed by an extended linkage disequilibrium analysis in the hemochromatosis gene region, two distinct peaks of association, namely a highly significant association at D6S2239, localized in close proximity to HFE (14 kilobases telomeric) and at D6S105 [24]. It the present work we use additional genetic markers in close proximity to the microsatellite D6S105 and found that this microsatellite marker itself was not associated with CD8+ T lymphocytes, but 3 other SNP markers defining a conserved $500 \mathrm{~Kb}$ haplotype and localized $400 \mathrm{~Kb}$ centromerically to D6S105, constitute the best markers described till now predicting CD8+ T-cell numbers and the phenotype of $\mathrm{HH}$. It is very unlikely that any of these SNP markers contribute directly to the setting of CD8+ T lymphocytes, therefore further studies, with extended genetic markers and with increased numbers of subjects, are needed.

\section{Conclusion}

These results may have important implications for approaching the question of the penetrance of the hemochromatosis gene in different world populations and also to further narrow the region of interest to find a candidate gene involved in the setting of CD8+ T-lymphocyte numbers in humans.

\section{Competing interests}

The authors declare that they have no competing interests.

\section{Authors' contributions}

EC and GP conceived and designed the study, diagnosed and treated the Portuguese hemochromatosis patients, compiled their clinical data, contribute to the interpretation of data and wrote the manuscript. Additionally, EC analyzed the data and performed the statistical analysis. CW diagnosed and treated the Canadian hemochromatosis patients. JV participated in the design of the study and contributed to the statistical analysis and its interpretation and to the writing of the manuscript. SK oversaw the performance and interpretation of most of the laboratory assays performed on the Canadian patients and assisted with correlations between clinical and laboratory findings. Additionally, CW and SK contribute to the interpretation and actively participate in the discussion of the results of the manuscript. CM performed the SNP genotyping of all patients. RL performed the T-cell immunophenotyping of the Portuguese patients. All authors read and approved the final manuscript.

\section{Acknowledgements}

We gratefully acknowledge Maria Graça Melo for assistance in Portuguese patients' recruitment and sample collection, and BC Biomedical Laboratories (7455 - 130th Street, Surrey BC, V3W IH8, Canada) for collection of samples from Canadian patients and consignment of the specimens to Porto.

Work supported by grants from the Portuguese Foundation for Science and Technology (FCT grant PTDC/SAU-GMG/67868/2006) and the Calouste Gulbenkian Foundation.

\section{References}

I. Pietrangelo A: Hereditary hemochromatosis-a new look at an old disease. N Engl J Med 2004, 350:2383-97.

2. Feder JN, Gnirke A, Thomas W, Tsuchihashi Z, Ruddy DA, Basava A, Dormishian F, Domingo R Jr, Ellis MC, Fullan A, Hinton LM, Jones NL, Kimmel BE, Kronmal GS, Lauer P, Lee VK, Loeb DB, Mapa FA, McClelland E, Meyer NC, Mintier GA, Moeller N, Moore T, Morikang $\mathrm{E}$, Wolff RK: A novel MHC class I-like gene is mutated in patients with hereditary haemochromatosis. Nat Genet 1996, 13:399-408.

3. Ryan E, Byrnes V, Coughlan B, Flanagan AM, Barrett S, O'Keane JC, Crowe J: Underdiagnosis of hereditary haemochromatosis: lack of presentation or penetration? Gut 2002, 5 I : I08-12.

4. Adams PC, Chakrabarti S: Genotypic/phenotypic correlations in genetic hemochromatosis: evolution of diagnostic criteria. Gastroenterology 1998, I | 4:319-323.

5. Piperno A, Sampietro M, Pietrangelo A, Arosio C, Lupica L, Montosi G, Vergani A, Fraquelli M, Girelli D, Pasquero P, Roetto A, Gasparini P, Fargion S, Conte D, Camaschella C: Heterogeneity of Hemochromatosis in Italy. Gastroenterology 1998, I | 4:96-1002. 
6. Rhodes DA, Raha-Chowdhury R, Cox TM, Trowsdale J: Homozygosity for the predominant Cys282Tyr mutation and absence of disease expression in hereditary haemochromatosis. J Med Genet 1997, 34:76I-4.

7. Olynyk JK, Hagan SE, Cullen DJ, Beilby J, Whittall DE: Evolution of untreated hereditary hemochromatosis in the Busselton population: a I7-year study. Mayo Clin Proc 2004, 79:309-I3.

8. Andersen RV, Tybjaerg-Hansen A, Appleyard M, Birgens H, Nordestgaard BG: Hemochromatosis mutations in the general population: iron overload progression rate. Blood 2004, 103:2914-9.

9. Allen KJ, Gurrin LC, Constantine CC, Osborne NJ, Delatycki MB, Nicoll AJ, McLaren CE, Bahlo M, Nisselle AE, Vulpe CD, Anderson G], Southey MC, Giles GG, English DR, Hopper JL, Olynyk JK, Powell LW, Gertig DM: Iron-overload-related disease in HFE hereditary hemochromatosis. N Engl J Med 2008, 358:22I-30.

10. Adams PC, Reboussin DM, Barton JC, McLaren CE, Eckfeld JH, McLaren GD, Dawkins FW, Acton RT, Harris EL, Gordeuk VR, Leiendecker-Foster C, Speechley M, Snively BM, Holup JL, Thomson E, Sholinsky P: Hemochromatosis and iron-overload screening in a racially diverse population. N Engl J Med 2005, 352:1769-78.

II. Beutler E, Felitti VJ, Koziol JA, Ho NJ, Gelbart T: Penetrance of 845G--> A (C282Y) HFE hereditary haemochromatosis mutation in the USA. Lancet 2002, 359:2।I-8.

12. Delatycki MB, Allen KJ, Nisselle AE, Collins V, Metcalfe S, du Sart D, Halliday J, Aitken MA, Macciocca I, Hill V, Wakefield A, Ritchie A, Gason AA, Nicoll AJ, Powell LW, Williamson R: Use of community genetic screening to prevent HFE-associated hereditary haemochromatosis. Lancet 2005, 366:3।4-6.

13. Deugnier $Y$, Jouanolle AM, Chaperon J, Moirand R, Pithois C, Meyer JF, Pouchard M, Lafraise B, Brigand A, Caserio-Schoenemann C, Mosser J, Adams P, Le Gall JY, David V: Gender-specific phenotypic expression and screening strategies in C282Y-linked haemochromatosis: a study of $\mathbf{9 3 9 6}$ French people. $\mathrm{Br} J \mathrm{Hae}-$ matol 2002, I I 8: I 170-8.

14. Olynyk JK, Cullen DJ, Aquilia S, Rossi E, Summerville L, Powell LW: A population-based study of the clinical expression of the hemochromatosis gene. N Engl] Med 1999, 34I:718-24.

15. Reimão R, Porto G, De Sousa M: Stability of CD4/CD8 ratios in man: new correlation between CD4/CD8 profiles and iron overload in idiopathic hemochromatosis patients. CRAcad Sci Paris 1991, 3 1 3:48I-483.

16. Porto G, Reimão R, Gonçalves C, Vicente C, Justiça B, de Sousa M: Haemochromatosis as a window into the study of the immunological system: a novel correlation between CD8+ lymphocytes and iron overload. Eur J Haematol 1994, 52:283-290.

17. Porto G, Vicente C, Teixeira MA, Martins O, Cabeda JM, Lacerda R, Goncalves C, Fraga J, Macedo G, Silva BM, Alves H, Justica B, de Sousa M: Relative impact of HLA phenotype and CD4/CD8 ratios on the clinical expression of hemochromatosis. Hepatology 1997, 25:397-402.

18. De Sousa M, Porto G: The immunological system in hemochromatosis. J Hepatol 1998, 28:1-7.

19. Porto G, Cardoso CS, Gordeu, Cruz E, Fraga J, Areias J, Oliveira JC, Bravo F, Gangaidzo IT, MacPhail AP, Gomo ZA, Moyo VM, Melo G, Silva $C$, Justica $B$, de Sousa $M$ : Clinical and genetic heterogeneity in hereditary haemochromatosis: association between lymphocyte counts and expression of iron overload. Eur J Haematol 200।, 67: I1 0-8.

20. Barton JC, Wiener HW, Acton R, Go RC: Total blood lymphocyte counts in hemochromatosis probands with HFE C282Y homozygosity: relationship to severity of iron overload and HLA-A and -B alleles and haplotypes. BMC Blood Disord 2005, 5:5.

21. Cruz E, Vieira J, Goncalves R, Alves H, Almeida S, Rodrigues P, Lacerda R, Porto G: Involvement of the major histocompatibility complex region in the genetic regulation of circulating CD8 T-cell numbers in humans. Tissue Antigens 2004, 64:25-34

22. Cruz E, Vieira J, Almeida S, Lacerda R, Gartner A, Cardoso CS, Alves $\mathrm{H}$, Porto G: A study of 82 extended HLA haplotypes in HFE. C282Y homozygous hemochromatosis subjects: relationship to the genetic control of CD8+ T-lymphocyte numbers and severity of iron overload. BMC Med Genet 2006, 7:16.

23. Vieira J, Cardoso CS, Pinto J, Patil K, Brazdil P, Cruz E, Mascarenhas C, Lacerda R, Gartner A, Almeida S, Alves H, Porto G: A putative gene located at the MHC class I region around the D6S I 05 marker contributes to the setting of CD8+ T-lymphocyte numbers in humans. Int J Immunogenet 2007, 34:359-67.

24. Pratiwi R, Fletcher LM, Pyper W, Do KA, Crawford DH, Powell LW, Jazwinska EC: Linkage disequilibrium analysis in Australian haemochromatosis patients indicates bipartite association with clinical expression. J Hepatol 1999, 31:39-46.

25. Haskins D, Stevens AR Jr, Finch S, Finch CA: Iron metabolism; iron stores in man as measured by phlebotomy. J Clin Invest 1952, 31:543-7.

26. Cruz E, Melo G, Lacerda R, Almeida S, Porto G: The CD8+ T-lymphocyte profile as a modifier of iron overload in HFE hemochromatosis: an update of clinical and immunological data from 70 C282Y homozygous subjects. Blood Cells Mol Dis 2006, 37:33-9.

\section{Pre-publication history}

The pre-publication history for this paper can be accessed here:

http://www.biomedcentral.com/1471-2350/9/97/prepub
Publish with Bio Med Central and every scientist can read your work free of charge

"BioMed Central will be the most significant development for disseminating the results of biomedical research in our lifetime. "

Sir Paul Nurse, Cancer Research UK

Your research papers will be:

- available free of charge to the entire biomedical community

- peer reviewed and published immediately upon acceptance

- cited in PubMed and archived on PubMed Central

- yours - you keep the copyright

Submit your manuscript here:

http://www.biomedcentral.com/info/publishing_adv.asp 